\title{
Langerhans cell histiocytosis of the atlas in an adult
}

\author{
Wo Quan Zhong • Liang Jiang • Qing Jun Ma • \\ Zhong Jun Liu $\cdot$ Xiao Guang Liu $\cdot$ Feng Wei $\cdot$ \\ Hui Shu Yuan · Geng Ting Dang
}

Received: 14 September 2009/Published online: 21 October 2009

(C) Springer-Verlag 2009

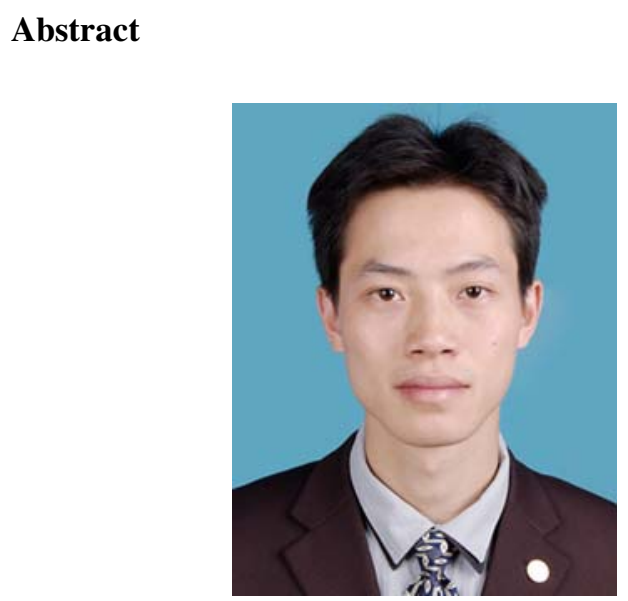

Langerhans cell histiocytosis (LCH), formerly known as histiocytosis $\mathrm{X}$, is a rare disorder (approximately $1: 1,500,000$ inhabitants) characterized by clonal proliferation and excess accumulation of pathologic Langerhans cells causing local or systemic effects. The exact etiology of LCH is still unknown. LCH could affect patients of any age, although most present when they are children. The most frequent sites of the bony lesions are the skull, femur,

W. Q. Zhong · L. Jiang $(\bowtie) \cdot$ Q. J. Ma ·

Z. J. Liu · X. G. Liu - F. Wei - G. T. Dang

Orthopaedic Department, Peking University Third Hospital,

No 49, North Garden Street, HaiDian District,

100191 Beijing, China

e-mail: jiangliang@bjmu.edu.cn

W. Q. Zhong

e-mail: zhong811@yeah.net

H. S. Yuan

Radiological Department, Peking University Third Hospital, 100191 Beijing, China mandible, pelvis and spine. A variety of treatment modalities has been reported, but there was no evidence suggesting that any one treatment was more advantageous than another. We present an adult with LCH of the atlas. A 26year-old young man presented with a 2-month history of neck pain and stiffness. CT revealed osteolytic lesion in the left lateral mass of atlas with compression fracture. Histopathological diagnosis was Langerhans cell histiocytosis by percutaneous needle biopsy under CT guidance. The patient underwent conservative treatment, including Halovest immobilization and radiotherapy. At 7-year follow-up, the patient was asymptomatic except for mild motion restriction of the neck. CT revealed a significant reconstruction of the $\mathrm{C} 1$ lateral mass.

Keywords Langerhans cell histiocytosis . Eosinophilic granuloma $\cdot$ Spine

\section{Case presentation}

A 26-year-old man presented with neck pain for 2 months and stiffness for 1 week. After acupuncture and physiotherapy, his symptoms gradually got worse, and he had to hold his head with his hands while sitting or standing up. The patient's medical history was unremarkable. Physical examination demonstrated obvious restriction of the neck motion without neurological deficit or torticollis.

\section{Diagnostic imaging section}

CT (Computed tomography) scan showed an osteolytic lesion in the left lateral mass of the atlas without soft tissue extension (Fig. 1). The laboratory findings such as blood 
Fig. 1 An osteolytic lesion with compression fracture in the left lateral mass of the atlas
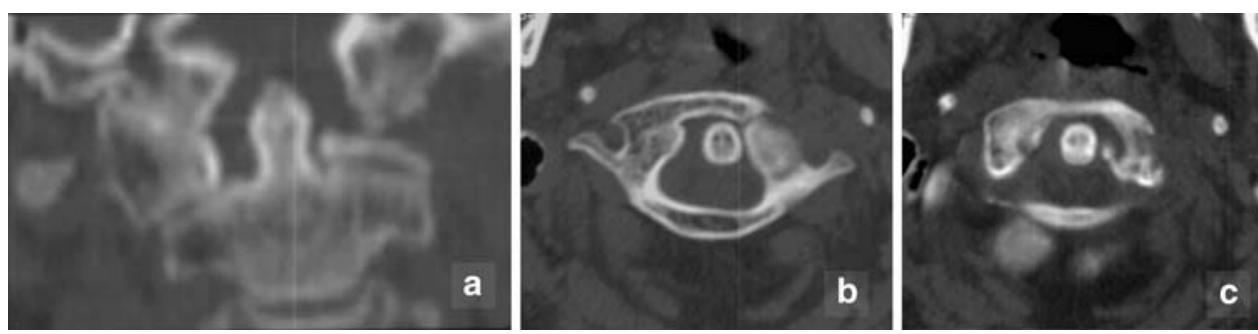

count and erythrocyte sedimentation rate (ESR) were unremarkable. A CT-guided percutaneous needle biopsy was performed and the histopathological diagnosis was eosinophilic granuloma (one subtype of Langerhans cell histiocytosis, LCH). No other lesion was found by bone scan.

\section{Historical review}

LCH encompasses three classic clinical syndromes that are considered to be clinical variations of the same disease: (1) eosinophilic granuloma (EG, benign form, isolated to bone and often monostotic), (2) Hand-Schüller-Christian disease (classic triad of skull lesions, exophthalmos, and diabetes insipidus), and (3) Letterer-Siwe disease (most malignant form, disseminated lesions involving multiple visceral organs) [2]. About $79 \%$ of all LCH bone lesions are solitary EGs, in $7 \%$ of cases multiple EGs are found, and $14 \%$ belong to other forms of LCH [3].

$\mathrm{LCH}$ in the spine is reported to range between 6.5 and $25 \%$ [6], with the most frequent site being the thoracic vertebra (54\%), followed by the lumbar (35\%) and cervical (11\%) vertebra [3]. Most of the LCH lesions are located in the vertebral body, and only $5 \%$ cases involve the posterior arch (pedicle, transverse process and lamina) [5]. Recent studies have reported that as many as 39\% LCH cases were adults and that spine lesion is less common in the adult group (3-10\%) [9]. More than half of the cervical LCH lesions affected the C3-5 vertebrae [15], and there were very few published cases describing Langerhans cell histiocytosis of the atlas. To the best of our knowledge, only $17 \mathrm{LCH}$ cases involving the atlas have been reported in the English literature $[4,6,10,13,15,16,19]$. Most cases had multiple vertebrae $[4,6,10]$ and/or extraspinal involvement [19]. Only one adult atlantal LCH case had been reported [4], and our case with solitary $\mathrm{C} 1$ lesion was the second.

The most common symptoms of LCH of the cervical spine are neck pain, restricted range of motion, or torticollis. And torticollis is often observed in axial LCH cases [13]. There is rarely history of trauma. Local deformity or atlantoaxial dislocation/subluxation might develop in some cases [19]. Neurological deficits are supposed to be rare
[19], but neurologic symptoms were as high as $33 \%$ in Bertram's review of 53 cervical LCH cases [3]. Our patient is an adult with neck pain and restricted range of motion.

The typical radiographic characteristics of vertebral LCH were as follows: (1) Only one vertebra is involved. (2) Vertebral plana or collapse of the vertebral body with homogeneous density. (3) Adjacent discs of the involved vertebra are intact. (4) Disc space is about a third wider than the next space above and below. (5) Absence of posterior arch or paravertebral extension [3, 21].

But this so called "classic radiographic findings" were originally based on clinical practice when there was neither CT nor MRI. CT and MRI can show the range of the bony lesion and the extension of soft tissue much more clearly, especially for tiny lesions in deep site which might be ignored by plain film [1]. With the prevalence of CT and/or MRI, soft tissue extension was reported in 50\% cases [14] and posterior arch extension in 65\% cervical LCH cases [11]. Isolated $\mathrm{C} 1$ posterior arch involvement [16] and cervical endplate destruction [11] have also been reported.

The laboratory findings are usually within normal range in the $\mathrm{LCH}$ patients, and none are diagnostic. ESR could be elevated in some patients $(22.2-38.2 \%)$ [11, 14]. Radiographic survey or bone scintigraphy should be suggested for LCH cases. These two techniques are complementary, and some authors have suggested the use of both modalities in the initial workup [2]. One of the two modalities may be sufficient for follow-up.

The basic pathologic finding of LCH is the Langerhans cell, which is an important component of the immune system. The diagnosis of LCH can be confirmed by the Birbeck granules under electron microscopy or performing immunohistochemical staining with CD-1a and S-100 protein. The specific feature of this disease is the proliferation of Langerhans cells and their accumulation in various tissues. The etiology of $\mathrm{LCH}$ is unknown exactly. It is considered to be a disorder of the immune system's immaturity, a neoplasm or some kind of infectious disease [2].

Biopsy is still controversial for the diagnosis of spinal LCH. Vertebral plana is seen in only $20 \%$ of the cases of cervical LCH in children [3]; and vertebral plana could exist in a variety of diseases, including Ewing sarcoma, metastasis, osteomyelitis, chordoma and tuberculosis. 
As mentioned previously, many spinal LCH cases had atypical findings. Anatomical structure of the atlas and axis is quite unique, which is even difficult to diagnose. Many authors suggested biopsy for a definitive diagnosis [19]. CT-guided percutaneous needle biopsies for spine lesions have been proved to be safe and effective [11]. If multiple skeletal sites or other system are involved, the most accessible site is the best candidate for biopsy. We routinely suggested biopsy for spinal LCH patients except those cases with typical radiography findings, who should be followed closely clinically and radiographically [6].

\section{Rationale for treatment and evidence-based literature}

The prognosis of $\mathrm{LCH}$ varies from spontaneous resolution to death. The bony $\mathrm{LCH}$ lesion is usually a self-limiting process. The treatment modality for spinal $\mathrm{LCH}$ is still not standardized. A variety of treatment modalities has been reported for bony LCH lesion, including observation, injections of steroid, radiation therapy, chemotherapy, local excision and curettage with or without bone grafting. Despite of the different treatments, the majority of the patients recovered well. There was no evidence suggesting that any one treatment was more advantageous than another [6] and surgery is not usually recommended.

Generally, mild isolated spine involvement can be satisfactorily treated with conservative measures such as simple observation, bracing, nonsteroidal anti-inflammatory drugs, or casting with or without initial bed rest [21]. Mammano [12] reported nine cases of spinal EG (311 years old) treated by cast or brace for average 21 months after 2 months of bed rest. Vertebral reconstruction was observed during an average 10-year followup. Puigdevall [15] reported complete bony reconstruction in two LCH cases of the altas, who were immobilized by hard collar for 3 months. Garg [6] stated that bracing and casting is unnecessary for single spinal lesions once pain subsides and the vertebral body begins to regain its height (usually several months after the onset of subjective symptoms). For atlantoaxial lesions, Garg [6] used Halovest immobilization, and Tanaka [19] suggested collar for 3 or 4 months.

Radiation therapy is also a controversial treatment. In many authors' opinion, radiation therapy should not be used as a first-choice due to the potential for secondary malignancy and vertebral growth-plate damage in the skeletally immature patient [3, 6]. Some authors believe that neurologic deficit is the only indication for radiotherapy [21] and others that it should be reserved for patients with progressive symptoms [6]. But significant bony reconstruction and spine realignment have been observed by many authors $[5,11,21]$. Secondary malignancy was only reported by only one study [8]. Low-dose radiotherapy still appears safe and effective for solitary LCH lesion, for us and other authors $[4,6,10]$.

Chemotherapy is suggested for the disseminated $\mathrm{LCH}$, such as multiple bone lesions or multi-system disease (Hand-Schüller-Christian disease or Letterer-Siwe disease). It has been proved to be safe and effective, which significant decrease in recurrence [20]. Paravertebral and extradural soft tissue extension could also disappear [14]. Tanaka suggested low-dose chemotherapy and collar immobilization for two $\mathrm{C} 1$ cases.

Local intralesional injection of corticosteroids has been suggested for the management of neurologic deficit [17]. This treatment should be performed after histopathological diagnosis. Two procedures are needed: one for biopsy and the other for intra-lesion corticosteroids injection, and the risk of iatrogenic injury might also be doubled.

Surgical indications include suspected malignancy, marked instability, deformity and/or neurological deficit due to compression [11]. Yeom analyzed 23 cases of LCH and noted that the four patients who underwent surgery, especially curettage and anterior fusion, had the worst outcome compared with other nonoperative modalities.
Fig. 2 Significant

reconstruction of the lateral mass of the atlas was observed at 7-year follow-up. The affected lateral mass got even denser comparing to the contralateral side
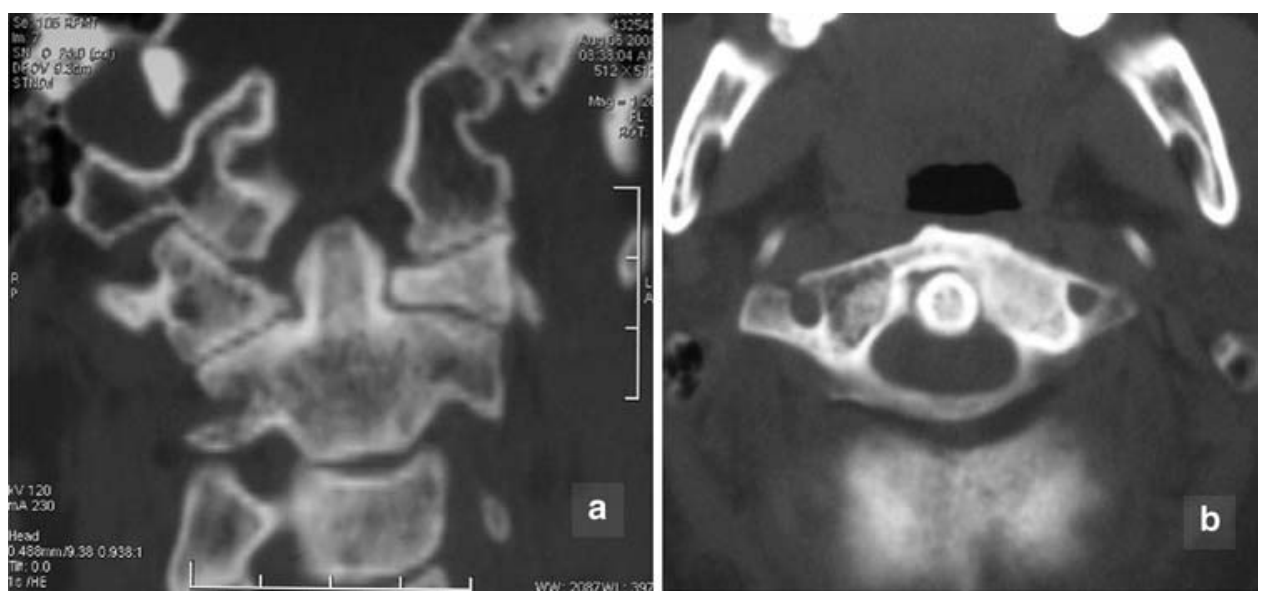
As the majority of lesions locate in the vertebral body, surgery will surely damage growing potential of the vertebral body, as the growth potential of the posterior elements remains. Local kyphosis may occur and progress, probably requiring additional posterior fusion. Therefore, surgery should be strictly reserved for selected cases with severe mechanical stability or progressive neurological deficit [3, 6, 15]. Four operations had been carried out for C1 LCH cases, including open biopsy, curettage $[4,16]$ and fixation [4, 19].

Some authors have tried new treatment for spinal $\mathrm{LCH}$. Tan [18] used percutaneous vertebroplasty (PVP) in a child of cervical LCH, which seems to aggressive for us. Goldberg [7] treated two cases of single-organ, single-site LCH with only prostaglandin inhibitors, both of whom sustained favorable clinical outcomes.

Randomized multicenter controlled trial is needed to find out the standard strategy for the LCH's treatment. Many studies have supported that the natural history of $\mathrm{LCH}$ of the spine is benign; therefore, most authors have recommended a conservative treatment for $\mathrm{LCH}$ spinal lesions without neurological or mechanical complication. $[3,21]$.

\section{Procedure and outcome}

For us, Halo-vest immobilization is ideal for the atlantoaxial lesions with subluxation or severe compression fracture. Considering this patient's progressive symptom and severe vertebral compression fracture, Halo-vest immobilization was suggested for 6 months followed by cervical collar immobilization for another 3 months. His neck pain resolved just several days after the Halo-vest immobilization. Considering the relatively low risk of the complications of radiotherapy in adults, radiation therapy with 3,000 cGy was performed. Seven years later, the patient is asymptomatic with a significant reconstruction of the bone lesion (Fig. 2). He had mild restriction of the neck motion, which did not affect his everyday life.

\section{References}

1. Aizawa T, Sato T, Tanaka Y, Kokubun S (2005) Signal intensity changes on MRI during the healing process of spinal Langerhans cell granulomatosis: report of two cases. J Spinal Disord Tech 18:98-101

2. Azouz EM, Saigal G, Rodriguez MM, Podda A (2005) Langerhans' cell histiocytosis: pathology, imaging and treatment of skeletal involvement. Pediatr Radiol 35:103-115
3. Bertram C, Madert J, Eggers C (2002) Eosinophilic granuloma of the cervical spine. Spine 27:1408-1413

4. Floman Y, Bar-On E, Mosheiff R, Mirovsky Y, Robin GC, Ramu N (1997) Eosinophilic granuloma of the spine. Pediatr Orthop (Br) 6(4):260-265

5. Garg S, Mehta S, Dormans JP (2003) An atypical presentation of Langerhans cell histiocytosis of the cervical spine in a child. Spine 28:E445-E448

6. Garg S, Mehta S, Dormans JP (2004) Langerhans cell histiocytosis of the spine in children. Long-term follow-up. J Bone Jt Surg Am 86:1740-1750

7. Goldberg SA, O'Connor SC, Sprinz PG (2008) Prostaglandin inhibitors in the treatment of single-system Langerhans cell histiocytosis: pharmacologic rationale and report of two cases. Pediatr Hematol Oncol 30:778-780

8. Greenberger JS, Crocker AC, Vawter G, Jaffe N, Cassady JR (1981) Results of treatment of 127 patients with systemic histiocytosis. Medicine (Baltimore) 60:311-338

9. Islinger RB, Kuklo TR, Owens BD, Horan PJ, Choma TJ, Murphey MD, Temple HT (2000) Langerhans' cell histiocytosis in patients older than 21 years. Clin Orthop Relat Res 379:231235

10. Levine SE, Dormans JP, Meyer JS, Corcoran TA (1996) Langerhans' cell histiocytosis of the spine in children. Clin Orthop Relat Res 323:288-293

11. Liu XG, Zhong WQ, Liu ZJ, Yuan HS, Jiang L, Ma QJ, Wei F, Dang GT (2009) Diagnosis and treatment of Langerhans cell histiocytosis of the cervical spine. Chin J Spine Spinal Cord 19(6):431-436

12. Mammano S, Candiotto S, Balsano M (1997) Cast and brace treatment of eosinophilic granuloma of the spine: long-term follow-up. J Pediatr Orthop 17:821-827

13. Ngu BB, Khanna AJ, Pak SS, McCarthy EF, Sponseller PD (2004) Eosinophilic granuloma of the atlas presenting as torticollis in a child. Spine 29(5):E98-E100

14. Peng XS, Pan T, Chen LY, Huang G, Wang J (2008) Langerhans' cell histiocytosis of the spine in children with soft tissue extension and chemotherapy. International Orthopaedics (SICOT) online

15. Puigdevall M, Bosio S, Hokama J, Maenza R (2008) Langerhans cell histiocytosis of the atlas in the pediatric spine: total reconstitution of the bone lesion after nonoperative treatment. A report of two cases. J Bone Jt Surg Am 90:1994-1997

16. Robert H, Dubousset J, Miladi L (1987) Histiocytosis X in the juvenile spine. Spine 12(2):167-172

17. Sessa S, Sommelet D, Lascombes P, Prevot J (1994) Treatment of Langerhans-cell histiocytosis in children. J Bone Jt Surg Am 76:1513-1525

18. Tan HQ, Li MH, Wu CG, Gu YF, Zhang H, Fang C (2007) Percutaneous vertebroplasty for eosinophilic granuloma of the cervical spine in a child. Pediatr Radiol 37:1053-1057

19. Tanaka N, Fujimoto Y, Okuda T, Nakanishi K, Sumida T, Manabe H, Ochi M (2005) Langerhans cell histiocytosis of the atlas. A report of three cases. J Bone Jt Surg Am 87:2313-2317

20. Von Stebut E, Schadmand-Fischer S, Bräuninger W, Kreft A, Doberauer C, Steinbrink K (2008) Successful treatment of adult multisystemic Langerhans cell histiocytosis with psoralen-UV-A, prednisolone, mercaptopurine, and vinblastine. Arch Dermatol 144:649-653

21. Yeom JS, Lee CK, Shin HY, Lee CS, Han CS, Chang H (1999) Langerhans' cell histiocytosis of the spine analysis of twentythree cases. Spine 24:1740-1749 